\title{
Fatigue and its associated psychosocial factors in cancer patients on active palliative treatment measured over time
}

\author{
Marlies E. W. J. Peters ${ }^{1}$ - Martine M. Goedendorp ${ }^{2}$ - Constans A. H. H. V. M. Verhagen ${ }^{1}$. \\ Gijs Bleijenberg ${ }^{3}$. Winette T. A. van der Graaf ${ }^{1}$
}

Received: 8 April 2015 / Accepted: 16 August 2015 / Published online: 3 September 2015

(C) The Author(s) 2015. This article is published with open access at Springerlink.com

\begin{abstract}
Purpose Fatigue is a frequently reported symptom by patients with advanced cancer, but hardly any prospective information is available about fatigue while on treatment in the palliative setting. In a previous cross-sectional study, we found several factors contributing to fatigue in these patients. In this study, we investigated the course of fatigue over time and if psychosocial factors were associated with fatigue over time.

Methods Patients on cancer treatment for incurable solid tumors were observed over 6 months. Patients filled in the Checklist Individual Strength monthly to measure the course of fatigue. Baseline questionnaires were used to measure disease acceptance, anxiety, depressive mood, fatigue catastrophizing, sleeping problems, discrepancies in social support, and selfreported physical activity for their relation with fatigue over time. Results At baseline 137 patients and after 6 months 89 patients participated. The mean duration of participation was 4.9 months. At most time points, fatigue scores were significantly higher in the group dropouts in comparison with the group participating 6 months (completers). Overall fatigue levels remained stable over time for the majority of participants. In the completers, $42 \%$ never experienced severe fatigue, $29 \%$ persisted being severely fatigued, and others had either an in-
\end{abstract}

Marlies E. W. J. Peters

marlies.peters@radboudumc.nl

1 Department of Medical Oncology (452), Radboud University Medical Center, PO Box 9101, 6500 HB Nijmegen, the Netherlands

2 Department of Health Sciences, University of Groningen, University Medical Center Groningen, Groningen, the Netherlands

3 Expert Center for Chronic Fatigue, Radboud University Medical Center, Nijmegen, the Netherlands creasing or decreasing level. Of the investigated factors, low reported physical activity and non-acceptance of cancer were associated significantly to fatigue.

Conclusion A substantial number of participants never experienced severe fatigue and fatigue levels remained stable over time. For those who do experience severe fatigue, nonacceptance of having incurable cancer and low self-reported physical activity may be fatigue-perpetuating factors.

Keywords Advanced cancer · Fatigue · Quality of life · Palliative phase $\cdot$ Cancer treatment

\section{Introduction}

The main aim of cancer treatment in patients with advanced incurable cancer is prolonging patients' life while ideally maintaining patients' quality of life. Patients with advanced cancer described fatigue to be their most distressing symptom limiting their quality of life $[8,28]$. Although the knowledge of prevalence of fatigue, its course, and related factors in cancer survivors is extensive [1,10,17], the literature in patients with advanced cancer is scarce and prospective research in patients on active palliative cancer treatment is even more limited.

With the new treatment options nowadays, the palliative phase for patients with advanced cancer can last for years $[20,27]$ and has been compared with a chronic illness [40]. When we are able to prolong patients' life for years in the palliative phase, attention towards the occurrence of fatigue in this disease trajectory is relevant. In patients with advanced cancer, prevalence rates of fatigue of 33-90\% have been reported [7, 36, 38, 41]. Some researchers have suggested that fatigue will increase when a patient moves further in his palliative trajectory, in particular when being on active treatment 
$[5,7,34]$. Regrettably, most studies in patients within the palliative trajectory have studied pooled data of patients at different phases of their disease trajectory up to the final terminal phase $[5,7,34]$. Also, the majority of studies that report on fatigue in patients receiving palliative chemotherapy had not been designed to investigate fatigue as a primary research question. Some studies investigated fatigue in patients with advanced cancer when admitted to a palliative care unit or hospital for serious health deterioration [12, 18, 29, 36, 37]. These patients were mostly at a late palliative stage or terminal phase and did not receive anticancer treatment. In an observational study aimed at fatigue during anticancer therapy in 99 patients with different stages of disease, fatigue levels remained stable over 2 months [6]. We reported in a crosssectional study severe fatigue in $47 \%$ palliative patients on anticancer treatment, with higher fatigue scores in patients who were receiving further lines of treatment [31]. A longitudinal study is needed to determine whether fatigue increases during palliative cancer treatment.

In cancer survivors, a model was developed to explain persistent severe fatigue obviously not associated to somatic factors [35], and in addition, a successful therapy based on this model was developed $[15,16]$. In the abovementioned cross-sectional study in patients with advanced cancer, we found several non-somatic factors associated to fatigue similar to those in cancer survivors [32]. The psychosocial factors such as nonacceptance of having incurable cancer, anxiety, depressive mood, fatigue catastrophizing cognitions towards fatigue, sleeping problems, discrepancy in (expected and experienced) social support, and low perceived physical activity were all associated to fatigue. In the current longitudinal study, we wanted to investigate these factors prospectively for their contribution to fatigue over time in patients with incurable cancer, while on treatment. Our hypothesis was that the same psychosocial factors are associated with fatigue over time and contribute to fatigue over time independently.

Exploring the factors related to the course of fatigue prospectively might bring us a step forward to the development of a treatment model, on which interventions for fatigue can be developed also in the palliative phase of cancer treatment.

\section{Patients and methods}

Between December 2008 and June 2010, patients on or about to start with treatment for advanced, incurable cancer from the departments of medical oncology of a university and a regional hospital in the southeastern part of the Netherlands were asked to participate in this study. Physicians preselected potentially eligible patients based on the following inclusion criteria: diagnosis of advanced, incurable cancer; able to receive palliative (symptom reducing and/or life prolonging) cancer treatment; and able to fill in and return questionnaires in Dutch. The main investigator (MP) approached potential participants by telephone. She informed them about the study and additional written information was sent to those who were interested in the study.

Participants from the university medical center had the opportunity to either complete the baseline questionnaires using a computer at the outpatient clinic (in combination with a regular visit to the clinic) or fill in a paper-and-pencil version at home. Patients from the regional hospital all received the paper-and-pencil version at home. After the baseline investigation, the fatigue questionnaire Checklist Individual Strength was sent every month for 6 months. Six months after inclusion, a final set of follow-up questionnaires was sent. A maximum of two telephone calls were made by the investigator to complete the baseline and follow-up data. For the monthly sent out fatigue questionnaires, no additional attempts were made to complete these. Permission to conduct the study was obtained from both institutional review boards of the participating hospitals, although this study did not fall under the Medical Research Involving Human Subjects Act. All participants provided verbal consent.

\section{Instruments}

General information on demographical characteristics, stage and type of cancer, and current treatment was obtained from a general questionnaire, eventually supplemented with data from medical records. Fatigue severity was assessed with the subscale fatigue of the Checklist Individual Strength (CIS). This subscale consists of eight items asking for fatigue severity over the last 2 weeks; each item is scored on a 7-point Likert scale; range is from 8 to 56 ; higher scores indicate more severe fatigue. The validated cut-off score of 35 or higher was used to determine severe fatigue $[42,43]$. This score of 35 is about two times the standard deviation (sd) above the mean score of healthy controls. The subscale physical activity, consisting of three items on a 7-point Likert scale, was used to measure self-reported physical activity. Higher scores are indicative for lower self-reported physical activity $[3,9]$. The CIS is a well-validated instrument with excellent psychometric properties [3, 9, 43].

Inappropriate coping with disease was measured with the subscale Acceptance of the Illness Cognition Questionnaire (ICQ) for chronic diseases. This subscale measures the degree of acceptance of having cancer and consists of six items on a 4-point scale from 1 (do not agree) to 4 (completely agree) [14]. It has shown good reliability with Cronbach's alpha coefficients ranging from 0.84 to 0.91 in patients with chronic diseases [13].

Anxiety was measured with the subscale anxiety of the Hospital Anxiety and Depression Scale (HADS) [19, 24, 
45]. To assess depressive mood, the subscale depression of the HADS was used [19, 24]. Both subscales consist of seven items on a 4-point Likert scale. The HADS is an extensively used and validated instrument [44].

Fatigue catastrophizing was measured by the Fatigue Catastrophizing Scale (FCS), consisting of 10 items on a 5point scale from 1 (never true) to 5 (all of the time true) $[4,21]$. Higher scores are indicative for more fatigue catastrophizing. A total score is derived by computing the mean of 10 ratings. This subscale has a good reliability with a Cronbach's alpha of 0.85 [21].

Sleeping problems were measured by the sleep subscale of the Symptom Checklist (SCL-90) [2], consisting of three items on a 5-point scale from 1 (not at all) to 5 (very much). Higher scores indicate lower quality of sleep. Patients were asked if they, during the last month, (a) slept well, (b) had difficulty with falling asleep, and (c) woke up early in the morning. This subscale has a good reliability with a Cronbach's alpha of 0.73 [2].
Discrepancy between the received and desired amount of social support was measured by the van Sonderen Social Support List-Discrepancies (SSL-D) [33], consisting of eight items on a 4-point scale. Scores for the SSL-D range from 8 to 32. Higher scores are indicative for a higher discrepancy. This instrument has a good reliability with a Cronbach's alpha of 0.95 [11].

\section{Statistical methods}

Descriptive statistics and frequencies were generated to determine the sample characteristics and the course of fatigue. To give insight into the course of fatigue, we also differentiated between a group who dropped out (group DO) and a group that still participated at 6 months (completers). The non-parametric Mann-Whitney test was used to investigate differences in fatigue scores between the groups DO and completers. A linear regression analysis (enter method) was performed to assess the relationship
Fig. 1 Flowchart of the number of participants at the different time points

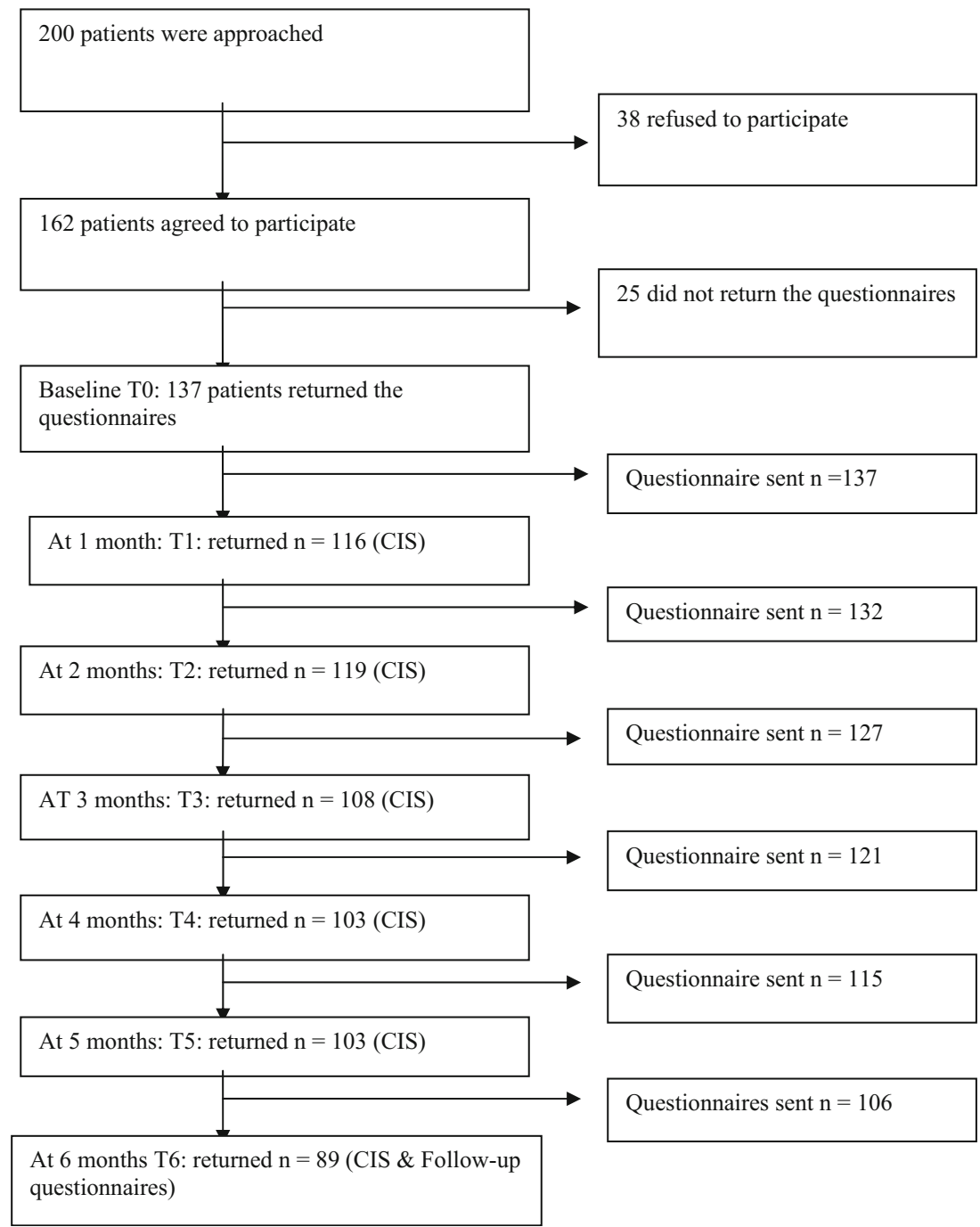


Table 1 Baseline demographic and cancer- and treatment-related characteristics

\begin{tabular}{ll}
\hline Characteristics & Participants, $n(\%)$ \\
\hline Participants & 137 \\
Female gender & $84(61)$ \\
Male gender & $53(39)$ \\
Mean age, years (range) & $59(30-79)$ \\
Marital status & \\
Married & $111(81)$ \\
Single (unmarried, divorced, widowed) & $26(19)$ \\
Type of cancer & \\
Breast & $41(30)$ \\
Gastrointestinal & $41(30)$ \\
Urogenital & $5(11)$ \\
Gynecological & $13(9.5)$ \\
Bone \& soft tissue & $13(9.5)$ \\
Other & $14(10)$ \\
Treatment modalities & \\
Chemotherapy & $72(53)$ \\
Oral-targeted therapy & $21(15)$ \\
Hormonal therapy & $20(15)$ \\
Chemo-targeted therapy & $19(14)$ \\
Radiotherapy & $2(1)$ \\
Chemoradiotherapy & $1(1)$ \\
No actual treatment & \\
Treatment line & $2(1)$ \\
First-line & \\
Second-line & $92(67)$ \\
Third-line & $28(20)$ \\
Fourth-line & $12(9)$ \\
\hline & $5(4)$ \\
\hline
\end{tabular}

${ }^{\mathrm{a}}$ Two patients were about to start with their first-line treatment

of psychosocial factors at baseline to fatigue over time. SPSS software (version 20) was used to analyze our data (SPSS Inc., Chicago, IL, USA).

\section{Results}

Two hundred patients with advanced cancer receiving treatment were approached for this study. One hundred and sixtytwo patients agreed to participate and 137 of them (69\%) filled in the baseline questionnaires. Non-participants $(n=63)$ did not differ from the participants with regard to sex, age, and cancer diagnosis as has been reported elsewhere [31]. Figure 1 shows the number of participants at the different time points. The mean duration of follow-up for all participants (AP) in the study, including dropouts, was 4.9 months. During the study period of 6 months, 89 patients participated during all 6 months (completers), the remaining 48 patients were considered as the group DO and they participated for a mean period of 2.7 months (range 1-5 months). Twelve of them only filled in the baseline measurements. Reasons for dropout were as follows: no longer being able to fill in questionnaires $(n=7)$, died during the study $(n=20)$, and not wanting to participate anymore $(n=4)$. Seventeen patients gave no reason for dropout. Demographic and cancer- and treatment-related characteristics of all participants at baseline are shown in Table 1. We found no significant differences between the groups DO and completers on gender, age, type of cancer, treatment modalities, and treatment line (not shown).

The mean fatigue scores and percentages of severely fatigued patients at the different time points of AP, of the group $\mathrm{DO}$, and the group completers are shown in Table 2. The mean fatigue scores in all three groups remained stable over time. At time points T1, T2, T3, and T4, the mean fatigue scores of the group DO were significantly higher in comparison with the completers. Also, the severely fatigued percentage remained quite stable over time within the group AP. The group DO showed an increase in percentages of severely fatigued patients during the first 2 months, and the completers showed the opposite. After the third month, the percentage of severely fatigued stabilized in both subgroups.

Table 2 Mean fatigue scores and percentages of severe fatigue during 6 months

\begin{tabular}{|c|c|c|c|c|c|c|c|}
\hline & \multicolumn{2}{|c|}{$\begin{array}{l}\text { All participants } \\
N=137\end{array}$} & \multicolumn{2}{|l|}{$\begin{array}{l}\text { Group dropout } \\
N=48\end{array}$} & \multicolumn{2}{|l|}{$\begin{array}{l}\text { Completers } \\
N=89\end{array}$} & \multirow{2}{*}{$\begin{array}{l}\text { Differences in mean } \\
\text { fatigue scores: group } \\
\text { dropout and completers } \\
P \text { value }\end{array}$} \\
\hline & $\begin{array}{l}\text { Mean fatigue } \\
(\mathrm{sd})\end{array}$ & $\begin{array}{l}\text { Severe fatigue, } \\
\%(n / N)\end{array}$ & $\begin{array}{l}\text { Mean fatigue } \\
\text { (sd) }\end{array}$ & $\begin{array}{l}\text { Severe fatigue, } \\
\%(n / N)\end{array}$ & $\begin{array}{l}\text { Mean } \\
\text { fatigue (sd) }\end{array}$ & $\begin{array}{l}\text { Severe fatigue, } \\
\%(n / N)\end{array}$ & \\
\hline Baseline/T0 & $32(13.2)$ & $47(64 / 136)$ & 35 (13.1) & $54(26 / 48)$ & $31(13.1)$ & $43(38 / 89)$ & 0.187 \\
\hline $\mathrm{T} 1$ & $32(12.9)$ & $46(53 / 116)$ & 38 (11.7) & $67(20 / 30)$ & $30(12.8)$ & $38(33 / 86)$ & 0.007 \\
\hline $\mathrm{T} 2$ & $32(12.8)$ & $40(48 / 119)$ & 38 (12.9) & $59(19 / 32)$ & 29 (11.9) & $33(29 / 87)$ & 0.001 \\
\hline $\mathrm{T} 3$ & $32(13.8)$ & $45(49 / 108)$ & $38(14.2)$ & $57(12 / 21)$ & $31(13.4)$ & $43(37 / 84)$ & 0.045 \\
\hline $\mathrm{T} 4$ & $31(13.9)$ & $44(45 / 103)$ & 39 (13.6) & $58(11 / 19)$ & $30(13.1)$ & $41(34 / 84)$ & 0.017 \\
\hline $\mathrm{T} 5$ & $31(13.8)$ & $44(45 / 103)$ & $38(13.0)$ & $50(7 / 14)$ & $31(13.4)$ & $43(38 / 89)$ & 0.082 \\
\hline T6 & $32(13.9)$ & $44(39 / 89)$ & & & 32 (13.9) & $44(39 / 89)$ & \\
\hline
\end{tabular}


Table 3 Linear regression to predict fatigue severity over the 6-month follow-up

\begin{tabular}{|c|c|c|c|c|}
\hline \multirow[t]{3}{*}{ Independent variables at baseline } & \multirow[t]{3}{*}{ Beta } & \multicolumn{3}{|c|}{$\begin{array}{l}\text { Dependent variable: mean CIS fatigue of all follow-up } \\
\text { assessments }\end{array}$} \\
\hline & & \multicolumn{2}{|l|}{$95 \%$ CI for $B$} & \multirow[t]{2}{*}{$P$ value } \\
\hline & & Lower bound & Upper bound & \\
\hline Acceptance $(n=89)$ & -0.263 & -1.366 & -0.045 & 0.037 \\
\hline Catastrophizing $(n=87)$ & 0.049 & -0.322 & 0.474 & 0.704 \\
\hline Depressive $\operatorname{mood}(n=86)$ & 0.204 & -0.169 & 1.635 & 0.110 \\
\hline Anxiety $(n=86)$ & -0.672 & -0.998 & 0.495 & 0.504 \\
\hline Sleep quality $(n=79)$ & -0.009 & -0.870 & 0.800 & 0.933 \\
\hline Discrepancies social support $(n=89)$ & -0.079 & -1.702 & 0.739 & 0.434 \\
\hline Self-reported physical activity $(n=88)$ & 0.504 & 0.580 & 1.406 & 0.000 \\
\hline
\end{tabular}

$R^{2}=0.514$

In the completers, $42 \%(37 / 89)$ never experienced severe fatigue and $29 \%(26 / 89)$ experienced severe fatigue at all time points. Thirteen patients became severely fatigued $(15 \%)$ and in 12 patients $(14 \%)$ it decreased in the 6-month follow-up, from severely to not severely fatigued. The linear regression analysis within the completers showed that $51 \%$ of the variance on fatigue severity may be explained by the psychosocial factors, of which the factors non-acceptance of having incurable cancer and self-reported physical activity contributed significantly to the severity of fatigue over the 6-month period (see Table 3).

Also the scores of the investigated psychosocial variables remained quite stable over time (see Table 4).

\section{Discussion}

In this study, we investigated the course of fatigue over a period of 6 months in patients with advanced cancer receiving palliative cancer treatment. Additionally, we prospectively explored which psychosocial factors contributed to the severity of fatigue over this period. To our knowledge, this is the first study in which the severity of fatigue is longitudinally observed in cancer patients on active treatment in the palliative phase.

Of the patients who were able to participate during the total period of 6 months, $42 \%$ were not severely fatigued and did not become so during this period. About a quarter of these patients was severely fatigued and remained so. In $15 \%$, a decrease from severe fatigue to non-severe fatigue occurred, and in $12 \%$ of patients, fatigue level increased from nonsevere to severe fatigue. Interestingly, in two thirds of the patients, the fatigue level did not change during the course of the study and the mean score was rather stable for the whole group participants during the 6-month study period. However, patients who dropped out somewhere during the study often had a significantly higher fatigue level at the various time points compared to the patients who remained in the study.

Although fatigue is the most often reported symptom in patients with incurable cancer [5, 36, 37], we demonstrated for the first time that not every patient suffers from severe fatigue. In the group of patients who remained in the study, the percentage of severely fatigued patients was lower compared with patients who dropped out. This might suggest that the patients who still participated after 6 months are part of a relatively fit group. This suggestion is supported by the finding of higher fatigue scores at baseline in the group who
Table 4 Baseline and follow-up values of investigated psychosocial factors

\begin{tabular}{|c|c|c|c|c|c|c|}
\hline \multirow[t]{2}{*}{ Variables } & \multicolumn{3}{|c|}{ Baseline } & \multicolumn{3}{|c|}{ Follow-up } \\
\hline & $N$ & Median & Interquartile range & $N$ & Median & Interquartile range \\
\hline Acceptance & 137 & 17 & 6 & 85 & 18 & 6 \\
\hline Catastrophizing & 133 & 16 & 7 & 86 & 18 & 9 \\
\hline Depressive mood & 134 & 4 & 4 & 87 & 4 & 5 \\
\hline Anxiety & 134 & 5 & 6 & 87 & 4 & 7 \\
\hline Sleep quality & 124 & 6 & 4 & 78 & 5 & 4 \\
\hline Discrepancies social support & 136 & 8 & 1 & 84 & 8 & 1 \\
\hline Self-reported physical activity & 137 & 12 & 9 & 82 & 11 & 11 \\
\hline
\end{tabular}


dropped out and by the finding that the main reason for dropout was deterioration of the health status or death. Moreover, the percentage of patients that changed levels of fatigue severity in the group that continued follow-up was rather low (29\%), suggesting that several factors perpetuate the fatigue during this observation period of 6 months. A study that would include all patients at the same time within their disease trajectory, i.e., at primary diagnosis of incurable cancer, and that will follow the patients longitudinally from that time onwards might provide more insight into the course of fatigue and associated symptoms.

Two of the investigated fatigue-associating factors were related to the course of fatigue (the mean fatigue score during the follow-up period), namely, a low level of self-reported physical activity and difficulties in acceptance of having incurable cancer. This implicates that influencing and addressing these factors might reduce fatigue and may have an improvement on the quality of life in these patients. Few studies already addressed the issue of physical activity and focused on exercise training to tackle fatigue but did not reach clinically relevant reductions in fatigue [30]. Other studies had small samples and mainly investigated the feasibility of exercise programs in patients in the palliative phase $[22,25,26]$. It is important to remark that in our study, we did not measure actual physical activity, for example by actimetry, but assessed the self-reported level of physical activity.

To reflect on the difficulties of acceptance of having incurable cancer relating to fatigue, we only found in literature that acceptance of having incurable cancer can be a specific factor for palliative patients. It has been described as a psychological process that evolves throughout the course of a disease trajectory [39]. To our awareness, however, this is the first study that found a relation with problems of acceptance with having incurable cancer and fatigue.

For five other postulated perpetuating factors, we could not show a relation with the course of fatigue in the palliative phase. There might be two reasons why we did not find such a relation. First, it could be explained by individual differences in relevance of these factors, an observation which has also been made in fatigue in cancer survivors [15, 32]. Second, it could be that we investigated the wrong factors. This would mean that factors other than postulated in our study may contribute to the course of fatigue. It is, however, difficult to state which factors we could have missed because literature on this topic is very scarce.

There are several limitations to be acknowledged. Although all participants had advanced cancer at baseline, the patients were not at the same point in their disease trajectory. At baseline, two patients were just about to start with their first-line treatment, while all other participants were somewhere within their disease trajectory varying from the first to the fourth treatment line. Regrettably, we have no information whether patients still received treatment at 6 months follow-up and if so, the kind of treatment or treatment line they were receiving at the final assessment, nor the effect on oncologic parameters. In line with this, we have no information on the median survival time of the participants.

Another limitation might be the questionnaires we used. We used the subscale anxiety of the HADS as a proxy for heightened fear of disease progression. We wanted to get more insight into fear related to having an incurable disease. At the time of study, such a validated questionnaire was not available in Dutch. Recently, such a questionnaire, the "fear of progression questionnaire," has been validated and this one could have been more suitable [23].

To summarize, an important conclusion from this study is that not all patients who continue active treatment within the palliative trajectory suffer from severe fatigue and only a minority change fatigue level over time. For those who do experience severe fatigue, non-acceptance of having incurable cancer and low perceived physical activity seem to be fatigueperpetuating factors. Fatigue interventions might therefore be directed at helping palliative patients to accept the cancer and improving their level of (subjective) physical activity.

Acknowledgments We would like to thank Tineke Smilde and Bernadine van de Walle - van de Geijn for approaching patients and coordinating the recruitment of potential participants at the Jeroen Bosch Hospital. Also, we would like to thank Lianne Vermeeren and Carel Kruip of the Expert Center Chronic Fatigue for entering all the data.

Funding Financial support was obtained from the Paul Speth Foundation.

Conflict of interest The authors declare that they have no competing interests.

Open Access This article is distributed under the terms of the Creative Commons Attribution-NonCommercial 4.0 International License (http:// creativecommons.org/licenses/by-nc/4.0/), which permits any noncommercial use, distribution, and reproduction in any medium, provided you give appropriate credit to the original author(s) and the source, provide a link to the Creative Commons license, and indicate if changes were made.

\section{References}

1. Ahlberg K, Ekman T, Gaston-Johansson F, et al. (2003) Assessment and management of cancer-related fatigue in adults. Lancet 362: $640-650$

2. Arrindell WEH, Groenman N, Brook F, Janssen I, Slaets J, Hekster G, Derksen J, Van Der Ende J, Land H, Hofman K, Dost S (2003) Further dutch experiences with the symptom checklist-90 - revised (De groeiende inbedding van de Nederlandse SCl-90-R, psychodiagnostisch gereedschap). De Psycholoog 11:576-582

3. Beurskens AJ, Bultmann U, Kant I, et al. (2000) Fatigue among working people: validity of a questionnaire measure. Occup Environ Med 57:353-357

4. Broeckel JA, Jacobsen PB, Horton J, et al. (1998) Characteristics and correlates of fatigue after adjuvant chemotherapy for breast cancer. J Clin Oncol 16:1689-1696 
5. Butt Z, Rosenbloom SK, Abernethy AP, et al. (2008) Fatigue is the most important symptom for advanced cancer patients who have had chemotherapy. J Natl Compr Cancer Netw 6:448-455

6. Butt Z, Wagner LI, Beaumont JL, et al. (2008) Longitudinal screening and management of fatigue, pain, and emotional distress associated with cancer therapy. Support Care Cancer 16:151-159

7. Collins S, De Vogel-Voogt E, Visser A, et al. (2008) Presence, communication and treatment of fatigue and pain complaints in incurable cancer patients. Patient Educ Couns 72:102-108

8. De Raaf PJ, De Klerk C, Timman R, et al. (2012) Differences in fatigue experiences among patients with advanced cancer, cancer survivors, and the general population. J Pain Symptom Manag 44: $823-830$

9. Dittner AJ, Wessely SC, Brown RG (2004) The assessment of fatigue: a practical guide for clinicians and researchers. J Psychosom Res 56:157-170

10. Donovan KA, Mcginty HL, Jacobsen PB (2013) A systematic review of research using the diagnostic criteria for cancer-related fatigue. Psychooncology 22:737-744

11. van Sonderen E (1993) het meten van sociale steun met de sociale steun lijst - interacties (SSL-I) en sociale steun lijst - discrepanties (SSL-D), een handleiding. In:Noordelijk centrum voor gezondheidsvraagstukken, Rijksuniversiteit Groningen

12. Echteld MAPJTS, Claessen S, De Wit R, Van Der Rijt CCD (2007) Multidimensional fatigue and its correlates in hospitalised advanced cancer patients. Eur J Cancer 43:1030-1036

13. Evers A, Fw K, Van LW, Jacobs J, Jwj B (1998) De ZiekteCognitie-Lijst (ZCL). Gedragstherapie, In

14. Evers AW, Kraaimaat FW, Van Lankveld W, et al. (2001) Beyond unfavorable thinking: the illness cognition questionnaire for chronic diseases. J Consult Clin Psychol 69:1026-1036

15. Gielissen MF, Verhagen CA, Bleijenberg G (2007) Cognitive behaviour therapy for fatigued cancer survivors: long-term follow-up. Br J Cancer 97:612-618

16. Gielissen MF, Verhagen S, Witjes F, et al. (2006) Effects of cognitive behavior therapy in severely fatigued disease-free cancer patients compared with patients waiting for cognitive behavior therapy: a randomized controlled trial. J Clin Oncol 24:4882-4887

17. Goedendorp MM, Gielissen MF, Verhagen CA, et al. (2013) Development of fatigue in cancer survivors: a prospective followup study from diagnosis into the year after treatment. J Pain Symptom Manag 45:213-222

18. Hauser K, Walsh D, Rybicki LA, et al. (2008) Fatigue in advanced cancer: a prospective study. Am J Hosp Palliat Care 25:372-378

19. Hopwood P, Howell A, Maguire P (1991) Screening for psychiatric morbidity in patients with advanced breast cancer: validation of two self-report questionnaires. Br J Cancer 64:353-356

20. Italiano A, Massard C, Bahleda R, et al. (2008) Treatment outcome and survival in participants of phase I oncology trials carried out from 2003 to 2006 at Institut Gustave Roussy. Ann Oncol 19:787792

21. Jacobsen PB, Andrykowski MA, Thors CL (2004) Relationship of catastrophizing to fatigue among women receiving treatment for breast cancer. J Consult Clin Psychol 72:355-361

22. Jensen W, Baumann FT, Stein A, et al. (2014) Exercise training in patients with advanced gastrointestinal cancer undergoing palliative chemotherapy: a pilot study. Support Care Cancer

23. Kwakkenbos L, Van Den Hoogen FH, Custers J, et al. (2012) Validity of the Fear of Progression Questionnaire-Short Form in patients with systemic sclerosis. Arthritis Care \& research 64: 930-934

24. Lloyd-Williams M, Friedman T, Rudd N (2001) An analysis of the validity of the Hospital Anxiety and Depression scale as a screening tool in patients with advanced metastatic cancer. J Pain Symptom Manag 22:990-996
25. Lowe SS, Watanabe SM, Courneya KS (2009) Physical activity as a supportive care intervention in palliative cancer patients: a systematic review. The Journal of Supportive Oncology 7:27-34

26. Maddocks M, Mockett S, Wilcock A (2009) Is exercise an acceptable and practical therapy for people with or cured of cancer? A systematic review. Cancer Treat Rev 35:383-390

27. Miller FG, Joffe S (2008) Benefit in phase 1 oncology trials: therapeutic misconception or reasonable treatment option? Clin Trials 5:617-623

28. Narayanan V, Koshy C (2009) Fatigue in cancer: a review of literature. Indian J Palliat Care 15:19-25

29. Okuyama T, Akechi T, Shima Y, et al. (2008) Factors correlated with fatigue in terminally ill cancer patients: a longitudinal study. J Pain Symptom Manag 35:515-523

30. Oldervoll LM, Loge JH, Lydersen S, et al. (2011) Physical exercise for cancer patients with advanced disease: a randomized controlled trial. Oncologist 16:1649-1657

31. Peters ME, Goedendorp MM, Verhagen CA, et al. (2014) Severe fatigue during the palliative treatment phase of cancer: an exploratory study. Cancer Nurs 37:139-145

32. Peters ME, Goedendorp MM, Verhagen SA, et al. (2014) Exploring the contribution of psychosocial factors to fatigue in patients with advanced incurable cancer. Psychooncology

33. Prins JB, Bos E, Huibers MJ, et al. (2004) Social support and the persistence of complaints in chronic fatigue syndrome. Psychother Psychosom 73:174-182

34. Respini D, Jacobsen PB, Thors C, et al. (2003) The prevalence and correlates of fatigue in older cancer patients. Crit Rev Oncol Hematol 47:273-279

35. Servaes P, Verhagen C, Bleijenberg G (2002) Fatigue in cancer patients during and after treatment: prevalence, correlates and interventions. Eur J Cancer 38:27-43

36. Spichiger E, Muller-Frohlich C, Denhaerynck K, et al. (2012) Prevalence and contributors to fatigue in individuals hospitalized with advanced cancer: a prospective, observational study. Int J Nurs Stud 49:1146-1154

37. Stone P, Hardy J, Broadley K, et al. (1999) Fatigue in advanced cancer: a prospective controlled cross-sectional study. Br J Cancer 79:1479-1486

38. Stone P, Richards M, Hardy J (1998) Fatigue in patients with cancer. Eur J Cancer 34:1670-1676

39. Thompson GN, Chochinov HM, Wilson KG, et al. (2009) Prognostic acceptance and the well-being of patients receiving palliative care for cancer. J Clin Oncol 27:5757-5762

40. Trajkovic-Vidakovic M, De Graeff A, Voest EE, et al. (2012) Symptoms tell it all: a systematic review of the value of symptom assessment to predict survival in advanced cancer patients. Crit Rev Oncol Hematol 84:130-148

41. Tsai JS, Chen SC, Chiu TY, et al. (2012) Correlates of fatigue phenomenon in palliative care patients with advance cancers in Taiwan. J Palliat Med 15:737-743

42. Vercoulen J, Hommes OR, Swanink CMA, et al. (1996) The measurement of fatigue in patients with multiple scleroses. A multidimensional comparison with patients with chronic fatigue syndrome and healthy subjects. Arch Neurol 53:642-649

43. Vercoulen J, Swanink CMA, Fennis JFM, et al. (1994) Dimensional assessment of chronic fatigue syndrome. J Psychosom Res 38:383392

44. Vodermaier A, Millman RD (2011) Accuracy of the Hospital Anxiety and Depression Scale as a screening tool in cancer patients: a systematic review and meta-analysis. Support Care Cancer 19: 1899-1908

45. Zigmond As SR (1983) The hospital anxiety and depression scale. Acta Psychiatr Scand 67:361-370 